\title{
Bilingual Teaching Research and Practice of Complex Function Theory
}

\author{
Lixin Ma (Corresponding author) \\ Department of mathematics, Dezhou University \\ Dezhou, Shandong Province, 253023 \\ E-mail: malixin0759@sina.com
}

The research is financed by the first bilingual program of demonstration projects of Shandong province, "Eleventh Five-Year" national issue (item code: FIB070335-A2-05)

\begin{abstract}
Mathematics bilingual teaching is assisted in Chinese with English teaching, and gradually enables students to independently use English to learn, study, reflect and exchange Mathematics. In order to better carry out mathematics teaching, department of mathematics in Dezhou University forms discussion groups and launches bilingual teaching practice of "complex function theory", which achieves good results.

Keywords: Mathematics, Complex function theory, Bilingual teaching, Practice

With the development of higher education reform, the training model, teaching mode and teaching method of higher education are undergoing major changes. In 2001, the ministry of education, in "some views on strengthening undergraduate teaching work to improve teaching quality" (high education [2001] 4), explicitly requires universities to actively carry out bilingual teaching study and practice of public education courses and specialized courses. In the following years, the ministry of education issued documents several times, where emphasizes the implementation of bilingual teaching curriculum requirements, and bring bilingual teaching into one of the important evaluation index of undergraduate teaching level evaluation. To this end, Dezhou University of Shandong province takes a series of measures to carry out this innovative education reform, and has launched the first batch of professional courses in English and Chinese bilingual teaching. Bilingual teaching of "complex function theory" is the first bilingual research issues. Bilingual teaching starts in mathematics and applied mathematics specialty in department of mathematics of 2005 grade in September of 2006, which belongs to professional courses. Blingual teaching has been carried out for three years and "complex function theory" is the highest college courses. Discussion group tries some ways of bilingual teaching in teaching experiments and explores the corresponding fundamental issues, which promotes awareness and has good results. To explore bilingual education rules and review and improve bilingual teaching methods and means, the research group concludes practice of bilingual teaching and learning activities in order to teach the peers.
\end{abstract}

\section{Bilingual teaching practice of "Complex Function Theory"}

"Mathematics language is an universal language". In mathematics language, the major terms are from foreign languages, and most of the symbols also come from English letters. Thus, bilingual teaching can strengthen mathematical language and mathematical basic skills training, and also adjust the subject development to train high-quality persons who understand English and specialty. The author believes that since bilingual teaching is bilingual, bilingual education not only teaches English and takes English as a foreign language, but takes English as a second language in the entire teaching process. Among them, the whole process of teaching should includes teaching materials, teaching reference books, teachers, lectures, tutoring, homework, exams and other factors

\section{1 solid material construction of Bilingual teaching course}

For bilingual education, selecting a suitable material is extremely important. Using foreign language materials or the adaptation materials depends on the circumstance. In general, foreign materials cover more exercises in large quantities, which is different with Chinese structural system. And its material selection and exercises are also very different from Chinese teaching materials. Some contents of it do not meet the requirements of syllabus and its ease degree departs from the actual acceptance of Chinese students.

I believe that, mathematics bilingual teaching about pending to the single English mathematics teaching takes original masters. Many classic original books have advised generations of mathematicians. These classic original books mostly are well-written by masters, where not only mathematics, but also their thinking ways, language, styles, and even their philosophy of life, research attitudes will be reflected. Students read those classic original masters and access things from center to local, which is stronger than reading those materials prepared patchwork.

After ministry of education issued a series of bilingual education and introduced original materials policy, a number of photocopies of foreign materials published in the domestic. These materials have been widely used in foreign countries, whose characteristics are high edition, detail teaching, abundant exercises, focusing on applications and 
wide use. Our group chooses "Complex Variables and Applications" (Seventh Edition) written by James Ward Brown and Ruel V. Churchill of the United States (published as a photocopy of outstanding foreign materials by China machine press in January, 2004). This book has been published for the seventh time in the United States. At the same time we select Chinese version book (Guanren Deng, who is professor of Beijing Normal University and doctor advisor, etc. translate it, published by China machine press).

The textbook covers generally same as the contents of complex functions in our current study(such as course material for the 21st Century (Zhong Yuquan, Second Edition)). The chapters are as follows: 1. Complex Numbers, 2. Analytic function, 3. Elementary function, 4. Integral, 5. Series, 6. Residue and pole, 7.Applications of Residue.

The book has common features with other good materials in the United States: Language is easy to understand and focuses on the visual interpretation of concepts and theorems. This book emphasizes on the train of quality and ability, and highlights academic thinking way and application. The point is new and content is appropriate. The content of this book is rich and method of justification and focus is different from other materials, which enables students to obtain broad knowledge. Most importantly, the book is more consistent with the actual level of students and curriculum of China. Through the use of this material, we can draw on the advanced teaching ideas and concepts to optimize our training model and higher teaching.

In order to help students remove barriers of learning English textbooks and promote the organic integration of academic knowledge and English knowledge, the research group has also prepared supplementary materials (total number of words is 100 000) to facilitate teaching. Supplementary materials include three aspects: The first is English vocabulary. Original professional materials typically have specialized new words and are difficult to remember. Then we write English vocabulary in accordance with section (including Word format and PPT format) for students to access and download. The second is technology English and professional English knowledge. Also shows the characteristics of professional English vocabularies, expressions of typical technology English, mathematical reading methods and basic points of writing English technology papers. The third is summary and problem solution in English form. Summarize the main content of original English materials and give detailed answers for some exercises.

\subsection{Teaching Design}

(1) Prepare lessons according to student's English and mathematical level. Classroom teaching is the center. Mathematical bilingual teaching not only considers the mathematical ability of students but also pays attention to the ability of understanding mathematics in English; Pay attention to not only the general lesson planning, but also special lesson planning. That is, in preparing lessons, teachers particularly consider the difficult point where understanding mathematics in English and care the students whose English and mathematics levels are low.

(2) Classroom teaching in English and Chinese. To ensure effectiveness of bilingual teaching, students should have good English listening and reading skills. According to positive and prudent principles and taking into account the student's current level, at first, only teach the English explanation of mathematical terminology. Slowly use English possibly in teaching definition and theorem. After teaching in English, repeat in Chinese. Keep abreast of the grasp condition in order to properly regulate the proportion of English and Chinese. Gradually increase the proportion of English teaching. For the focus and difficulty of classroom teaching, we should repeat in Chinese after explaining in English, so that students can not ignore the basic knowledge of mathematics learning based on studying technology English. In class, we pay attention to the main role of students, adopt a variety of ways to promote teacher-student interaction, base on creative ability and consider the guidance of mathematical thinking.

(3) Adopt combination of English courseware and English writing on blackboard to assist teaching. The blackboard mode must be suitable for explaining. As the English basis for our students are poor, when carrying out bilingual teaching in beginning, we first write in English on black board and teach in Chinese, then explain the English writing in order that the students can be familiar with English expression. The teaching contents and order should be consistent with the material so that student can collate in reviewing contents. For the difficulty of material, we can write in Chinese according to conditions in order that students can master. Through a period of training, students gradually master the common English expression in mathematics, then transit to write on blackboard and explain in English assisting with appropriate explanation in Chinese.

Multimedia assisted teaching. The time tension problem of bilingual teaching is prominent because it spends time to explain technical vocabulary, in particular, most students do not know the English pronunciation of mathematical formulas and symbols, even simple addition, subtraction, multiplication, division, fractions and inequality readings, and "Complex Variables and Applications" textbooks has large information and only 72 class hours. In order to teach materials using English, we must integrate the professional English knowledge into subjects, refine and concentrate the teaching contents, and effectively use multimedia courseware to assist teaching, so that in limited class time, 
ensure to impact the complex function subject knowledge and the normal teaching progress.

(4) Increase discussion in class. In the first semester of 2006-2007, second semester of 2006-2007, first semester of 2007-2008 and second semester of 2007-2008, we carried bilingual "complex function theory" teaching in mathematics and applied mathematics specialty of 2005 grade, information and computing science specialty of 2005 grade, mathematics and applied mathematics specialty of 2006 grade and information and computing science specialty of 2006 grade. After completing a chapter, give students a number of topics for self-study. Discuss based on self-study and let students write English paper and report it. Through that, not only train and exercise student's ability of self-study, but also students can find problems. And student's ability of solving problems improves. Students react it very effectively.

(5) Pay attention to application aspects and integrate mathematics model idea in teaching. Assorting with the course of "mathematical modeling and experiment" in our department, combine mathematics and modeling, and fully mobilize and exert enthusiasm of teachers, which further enhances the student's interest in this course and inspire students initiative to participate "Mathematical Modeling Competition" for the annual selection of "Mathematical Modeling Competition". My school has obtained second prize of country and first prize of province two good results, which makes other students to have interest in this course.

(6) Focus on student's feedback and improve our teaching. Direct purpose of bilingual teaching is to master the mathematical knowledge and learn English. These two facets are closely related. Master degree of student in a stage is a gist for determining the teaching method of the next stage. When evaluating master degree, we should consider the results of mastering mathematics and learning mathematical professional English. The way adopted takes the answer situation of classroom questions, conduct periodic survey and organize students to participate discussions, also encourage students to communicate with teachers by writing or by word of mouth for the views of bilingual teaching and the difficulties encountered.

(7) Develop the second class actively. On one hand, encourage students to actively participate English reports that school organizes, then use English class teaching, train professional English listening, inspire identity and urgency sense of students learning bilingual, help students gradually build thinking awareness in English, and improve English listening ability of students. On the other hand, actively invite external experts to conduct seminars, exchange academic communion with students, and increase learning interest of students.

\subsection{Reform examination and assessment methods}

Course evaluation contains two parts: annual assessment and final examination.

(1) Busywork assessment result (10\%). Peacetime busywork of students is required to answer in full English and specification statements should be complied with English criterion.

(2) Ordinary performance result (10\%). Take the performance of students inside and outside of classroom into the final examination result, which improves the student's positivity of exploring problem, transits from simple book study to research study, and improves the thinking ability of students.

(3) Speech or essay (10\%). After each chapter, students should do English speaking or report a small technology paper in class. The teachers comment speech and essay, and the score is taken into final grade.

(4) Final exam (70\%). Department of mathematics prepare a test bank. Each test is selected from the test bank, and according to teaching situation amending it to use. Final exam is closed and in full English and the answer is required in English. After the exam, the busywork should be inspected by line, the score test is organized strictly which reaches scientific, standardized in order to be reasonable, neat, do not be given mutual affection and rational distribution of student achievement. Detailed exam analysis should be written after exam, and the test, answer, marking criteria, paper together with paper analysis are delivered to office for keep in the archives.

\section{Problems considered in "Complex function theory" bilingual teaching}

(1) Fully mobilize initiative of students to participate bilingual teaching.

(2) Deal with conflict between professional theory and English learning.

(3) How to deal with difference between foreign material and domestic material: Owing to the distinctness of educational system, "complex function" book of our university is greatly different from the English original materials. It is difficult to find entirely appropriate English original material to carry out "complex function theory" bilingual teaching. Although the materials contents are same with the popular materials, such as "complex function theory" written by Yuquan Zhong, but also there are some differences.

(4) Consider how to incarnate the advanced teaching philosophy, and use international modern teaching and 
education methods for references.

(5) Keep abreast of reflection of students and improve teaching methods.

(6) Enhance vitality of classroom teaching.

(7) Encourage students to read English reference books after classroom.

(8) Proportion between Chinese and English in bilingual teaching: Speaking more Chinese should lose the meaning of bilingual teaching and speaking more English does not be understood much by students.

\section{Experience of "Complex function theory" bilingual teaching}

(1). The major problem encountered in bilingual teaching is to improve the teaching quality. But there are many factors affecting the course quality, where lack expression of teachers is an important factor. Bilingual teaching demands teachers highly. Non-standard speech and not standardized syntax not only directly affect professional knowledge learning, but also mislead students. Therefore, to improve the teaching quality, we must first improve the quality of teachers. Qualified university should organize teachers in bilingual teaching to be short-term trained in country where English is its mother language. In this way, we can not only realize the foreign subjects trends, but also learn advanced teaching methods and improve their English level.

(2). "Complex function theory" bilingual teaching is a significant educational reform. We conducted a series of exploration and practice to issues, such as teaching materials methods, teaching evaluation, and so on. But those are still preliminary and need further work. I think as long as we combine the fact of students in practice step by step and note experiences, we must be able to push "bilingual teaching" work in depth.

(3). Through "Complex function theory" teaching, we should make students able to realize the development of complex functions, the background for thinking and method of "Complex function theory" and the effect of "Complex function" mathematics development, and also get rid of the curriculum model that "only see the woods and not see the forest" in .

(4). Consciousness and ability culture of application time for students is a long-term goal. Therefore, reforming teaching method, changing teacher education concept and setting students in main body of teaching are the main task of the future teaching reform, which deserve further intensive study and practice.

(5). By "Complex function theory"'" bilingual study, students should master advanced professional knowledge and its application, flexibly use English tools, and improve the application ability of professional foreign language in the process of studying course knowledge. We should train students autonomy and awareness consciousness, promote innovative ability and overall quality, and inspire students autonomy and inquiry for creating international talents.

Try our best to construct "complex function theory" bilingual teaching to a model radiation curriculum, where "subject knowledge and applied English knowledge integrate, academic foundation and frontier integrate, knowledge imparting and culture of ability and quality integrate, and features of bilingual teaching is distinct.

\section{References}

Yonggang Zhu. (2006). Teaching Reformation of Engineering Complex Function. Studies in College Mathematics, (3):62-64.

Junku Cui. (2008). Practice and Key Points of bilingual teaching in College Course. The Science Education Article Collects, (8).

Yanhua Chu. (2007) . Bilingual Teaching Reform. Computer Education, (16).

Xiaoye Cai. (2005). Bilingual teaching. Computer Education, (7).

Lianghuan Lv. (2001). Bilingual teaching . Global Education, 2001 (4).

Binhua Wang. Comparison between China and foreign of bilingual teaching. [Online] Available: www.xinhuanet.com 